\title{
Lipoprotein apheresis affects lipoprotein particle subclasses more efficiently compared to the PCSK9 inhibitor evolocumab, a pilot study.
}

Knut Tore Lappegård, Christian Abendstein Kjellmo, Stefan A Ljunggren, Karin Cederbrant, Maritha Marcusson-Ståhl, Monica Mathisen, Helen Karlsson and Anders Hovland

The self-archived postprint version of this journal article is available at Linköping University Institutional Repository (DiVA):

http:/ / urn.kb.se/ resolve?urn=urn:nbn:se:liu:diva-146043

N.B.: When citing this work, cite the original publication.

Lappegård, K. T., Kjellmo, C. A., Ljunggren, S. A, Cederbrant, K., Marcusson-Ståhl, M., Mathisen, M., Karlsson, H., Hovland, A., (2018), Lipoprotein apheresis affects lipoprotein particle subclasses more efficiently compared to the PCSK9 inhibitor evolocumab, a pilot study., Transfusion and apheresis science, 57(1), 91-96. https:// doi.org/ 10.1016/j.transci.2018.01.002

Original publication available at:

https:/ / doi.org/ 10.1016/j.transci.2018.01.002

Copyright: Elsevier (12 months)

http:// www.elsevier.com/

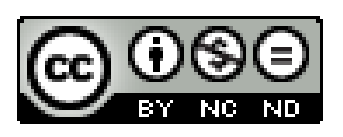




\section{Lipoprotein apheresis affects lipoprotein particle subclasses more efficiently}

compared to the PCSK9 inhibitor evolocumab, a pilot study

Knut Tore Lappegård ${ }^{1,2}$, Christian Abendstein Kjellmo ${ }^{1}$, Stefan Ljunggren ${ }^{3}$, Karin Cederbrant $^{5}$, Maritha Marcusson-Ståhl ${ }^{5}$, Monica Mathisen ${ }^{6}$, Helen Karlsson ${ }^{3}$, Anders Hovland ${ }^{1,2}$

${ }^{1}$ Division of Internal Medicine, Nordland Hospital, Bodø, ${ }^{2}$ Institute of Clinical Medicine, University of Tromsø, Troms $\varnothing$, Norway, ${ }^{3}$ Occupational and Environmental Medicine Center, and Department of Clinical and Experimental Medicine, Linköping University, Linköping, Sweden, ${ }^{5}$ Swedish Toxicology Sciences Research Center, Södertälje, Sweden ${ }^{6}$ Research Laboratory, Nordland Hospital, Bodø, Norway.

Corresponding author:

Anders Hovland

Division of Internal Medicine

$\mathrm{N}-8092$ Bodø

Norway

E-mail: anders.w.hovland@gmail.com

Telephone: +4775534000

Telefax: +4775534742

\section{ACKNOWLEDGMENTS}

The research group has received an unrestricted research grant from Amgen, Norway. The authors report no conflict of interest. 


\section{ABSTRACT}

Lipoprotein apheresis and proprotein convertase subtilisin/kexin type 9 (PCSK9) inhibitors are last therapeutic resorts in patients with familial hypercholesterolemia (FH). We explored changes in lipoprotein subclasses and high-density lipoprotein (HDL) function when changing treatment from lipoprotein apheresis to PCSK9 inhibition.

We measured the levels of low-density lipoprotein (LDL) and HDL particle subclasses, serum amyloid A1 (SAA1), paraoxonase-1 (PON1) activity and cholesterol efflux capacity (CEC) in three heterozygous FH patients. Concentrations of all LDL particle subclasses were reduced during apheresis (large $68.0 \pm 17.5$ to $16.3 \pm 2.1 \mathrm{mg} / \mathrm{dL}$, $(p=0.03)$, intermediate $38.3 \pm 0.6$ to $5.0 \pm 3.5 \mathrm{mg} / \mathrm{dL}(p=0.004)$ and small $5.0 \pm 2.6$ to $0.2 \pm 0.1 \mathrm{mg} / \mathrm{dL}(p=0.08))$. There were non-significant reductions in the LDL subclasses during evolocumab treatment. There were non-significant reductions in subclasses of HDL particles during apheresis, and no changes during evolocumab treatment. CEC was unchanged throughout the study, while the SAA1/PON1 ratio was unchanged during apheresis but decreased during evolocumab treatment.

In conclusion, there were significant reductions in large and intermediate size LDL particles during apheresis, and a non-significant reduction in small LDL particles. There were only non-significant reductions in the LDL subclasses during evolocumab treatment.

Keywords: LDL-cholesterol; lipoprotein particles, lipoprotein apheresis, PCSK9inhibition. 


\section{Introduction}

Lipoprotein apheresis has been considered the last treatment option when conventional cholesterol lowering treatment is not tolerated or when treatment targets are not met, particularly in patients with familial hypercholesterolemia $(\mathrm{FH})[1,2]$. The proprotein convertase subilisin/kexin type 9 (PCSK9) inhibitors are effective in reducing LDL cholesterol in heterozygous $\mathrm{FH}$ patients [3], and they also reduce coronary atheroma size [4]. The first clinical endpoint study with evolocumab was published in March 2017 and showed significant reductions in hard clinical endpoints [5]. Our group has recently demonstrated that when switching from lipoprotein apheresis to PCSK9 inhibition the LDL reduction is partly maintained, while avoiding reduction in high-density lipoprotein (HDL) cholesterol [6], furthermore PCSK9 inhibition elicits less inflammatory response than lipoprotein apheresis [7].

In addition to focus on LDL and HDL cholesterol there has been a growing interest in subclasses of lipoprotein particles, and traditionally small dense LDL particles have been considered particularly atherogenic [8-10]. The clinical effect of subclassing HDL particle size is perhaps more uncertain and the results have been more conflicting [11]. However, HDL composition and function have in recent times been assigned greater importance in lipid metabolism [12-14]. Paraoxonase-1 (PON1) is a HDL associated protein with anti-atherosclerotic properties by preventing oxidation of LDL and cell membranes [15]. Another crucial component of HDL is the acute phase protein serum amyloid A (SAA). Increased expression of SAA, as a result of infection or inflammation, alters the HDL composition and reduces the anti-inflammatory effects of HDL [16]. Regarding HDL functionality, research in reverse cholesterol transport including efflux capacity, has increased in recent years, and indeed efflux capacity is inversely associated with cardiovascular endpoints [17]. Contrary to previous research, small 
HDL particles seem to be associated with more effective cholesterol efflux [18], underlining the difficulties in interpreting cholesterol efflux data.

In the present study, we explored subclasses of LDL and HDL particles, cholesterol efflux capacity, PON1 activity and SAA1, when switching from lipoprotein apheresis to PCSK9 inhibition with evolocumab. 


\section{Material and Methods}

The study design and results regarding lipid and inflammatory parameters have recently been published $[6,7]$. In brief, it was an observational study with three $\mathrm{FH}$ patients established in long-term lipoprotein apheresis. They were all heterozygous for the C210G missense mutation in the LDL receptor gene [19]. Treatment was converted to a PCSK9 inhibitor (evolocumab), and the patients were examined immediately before and after their last apheresis treatment (week 0), after one week (immediately before the first evolocumab injection (week 1)), then biweekly before administration of evolocumab (weeks 3, 5 and 7)

\subsection{Patients and ethics}

There were two women (52 and 53 years) and one man (49 years) with genetically confirmed $\mathrm{FH}$, and they all had angiographically verified coronary artery disease. They were intolerant to statins due to myalgia, and they did not take any type of lipid lowering medication. The patients had been in lipoprotein apheresis on average for 11 years (11-13 years). All patients signed informed consent and the regional ethics committee approved the study. These were the only heterozygous $\mathrm{FH}$ patients in long term lipoprotein apheresis in Northern Norway. 


\subsection{Lipoprotein apheresis}

The patients were established in weekly filtration lipoprotein apheresis, and the last lipoprotein apheresis in week 0 was performed with the semi-selective LDL filtration column Cascadeflo-EC-50W (Asahi Kasei Medical Europe) after previous plasma separation with Plasmaflo OP-50 (Asahi Kasei Medical Europe), using the Infomed HF440 apheresis machine (Infomed SA, Geneva, Switzerland), for all three patients a plasma volume of $4000 \mathrm{~mL}$ was treated. Anticoagulation was obtained by unfractionated heparin (7500 units was given for priming the unit, then an individualized infusion was administered to each patient in order to avoid clotting (range 150 to 750 units per hour, average treatment times 2 hours and 15 minutes).

\subsection{Evolocumab treatment}

Evolocumab was administered according to the manufacturers' instructions in week one, three, five and seven with the recommended dose of $140 \mathrm{mg}$ subcutaneously (autoinjector). The injections were performed by the patients in the hospital, supervised by experienced nurses, after demonstrations with dummy autoinjectors.

\subsection{Blood samples and analyses}

Fasting blood samples were obtained by standard venipuncture (or from the AVfistulas during apheresis). Blood samples for plasma preparation were placed on ice before centrifugation for $20 \mathrm{~min}, 3000 \mathrm{xg}$ at $4^{\circ} \mathrm{C}$. Serum, EDTA plasma and citrate plasma were frozen in aliquots at $-80^{\circ} \mathrm{C}$ and analyzed in batch at the end of the study. 
LDL and HDL subfractions were determined electrophoretically by the use of lipid stained serum (Sudan Black), high-resolution 3\% polyacrylamide geltubes and the Lipoprint ${ }^{\circledR}$ system (Quantimetrix Corporation, Redondo Beach, CA, USA, [20]). The different subfractions were identified by their migration distance - on basis of size - in the gel and the concentration of each subfraction was calculated using the Lipoprint analysis software. The Lipoprint LDL system can identify seven subfractions of LDL, (1= larger, buoyant particles, 2= intermediate and 3-7= small, dense particles). The diameter of the LDL particles at the cut-off point separating subfractions 1-2 from 3-7 was $251 \AA$. The Lipoprint HDL system separates ten various HDL subfractions (1-3= large HDL particles, 4-7= intermediate HDL particles, 8-10= small HDL particles). Hence the different subfractions of LDL and HDL were divided into three subclasses; large, intermediate and small.

Cholesterol efflux was measured with a commercial kit from Sigma-Aldrich (MAK192) according to the description. Briefly, a human monocyte cell line, THP-1, was differentiated into macrophages with $10 \mathrm{ng} / \mathrm{ml}$ phorbol myristate acetate (PMA) for 24 hours at $37^{\circ}$ and $5 \% \mathrm{CO} 2$ in a 96 -well plate. The PMA containing medium was replaced with complete cultivation medium (RPMI640 including 10\% foetal bovine serum, $2 \mathrm{mM}$ Glutamine) and incubated for another 30 hours. The serum containing medium was removed and then washed with serum free medium. A reaction mix, containing equilibration buffer and fluorescence labelled LDL, was added to the cells and incubated for 16 hours. The reaction mix was removed and wells washed with serum free medium. Patient serum samples were precipitated with a reaction mix from the kit and the clear supernatant was added to the plate and incubated for 5 hours. After the incubation, supernatants were transferred to a new plate and the 
fluorescence measured (482 ex/515 em). The cell layer was solubilized with a cell lysis buffer, incubated for 30 minutes on a shaker. The cell lysate was then transferred to the plate with supernatants and the fluorescence of the mixture was measured. Percent efflux was calculated as follows: 100 x fluorescence intensity of the medium / $\mathrm{x}$ fluorescence intensity of the medium and cell lysate.

PON1 arylesterase activity was measured in citrate plasma. Briefly, plasma was diluted 1:80 with a salt buffer $\left(20 \mathrm{mM}\right.$ Tris $-\mathrm{HCl}$ and $\left.1.0 \mathrm{mM} \mathrm{CaCl}_{2}\right)$. A triplicate of 20 $\mu$ diluted plasma were added to the wells in an UV-transparent 96-well plate (SigmaAldrich). $200 \mu \mathrm{l}$ of phenyl acetate solution, containing $3.26 \mathrm{mM}$ phenyl acetate in salt buffer, was added to each well and the absorbance of produced phenol was measured at $270 \mathrm{~nm}$ with $250 \mathrm{~nm}$ as background in a SpectraMax 190 plate reader (Molecular Devices, Sunnyvale, CA, USA). The initial period when the reaction was linear was used for calculation of activity, expressed as $\mathrm{U} / \mathrm{ml}$, using an extinction coefficient of phenol of $1310 \mathrm{M}-1 \mathrm{~cm} 1$.

To investigate the acute phase response by SAA, plasma SAA1 levels were measured by an ELISA (DY3019-05, R\&D systems, Minneapolis, MN, USA) according to the manufacturers' instructions. In short, citrate plasma was added to the plate and incubated for 2 hours at room temperature. Following wash, a detection antibody was added and incubated for 2 hours. The plate was washed and streptavidin-horseradish peroxidase was added followed by incubation for $20 \mathrm{~min}$. The plate was then washed a final time before a substrate solution was added before 20 min incubation. At the end of the incubation, stop solution was added and 
absorbance was measured at $450 \mathrm{~nm}$ with correction at $570 \mathrm{~nm}$ using a Spectramax 190 plate reader (Molecular devices, Sunnyvale, CA, USA).

The measures of SAA and PON1 were integrated as SAA1/PON1 ratio, which has been proposed as a possible biomarker for dysfunctional HDL [21]. 


\subsection{Statistics}

Numerical data are presented with mean and standard deviation (SD). Age and duration of treatment are presented as mean and range. A repeated measures oneway analysis of variance (RM one-way ANOVA) was used to calculate the longitudinal effect of the evolocumab treatment (week one to week seven). Levels before and after lipoprotein apheresis treatment (week 0) and before apheresis vs. after the last evolocumab injection were compared by paired t-tests. All tests were two-tailed and results with a $p<0.05$ were considered statistically significant. Analyses were performed using PRISM 6 (Graph Pad Software Inc, La Jolla, CA, USA). 


\section{Results}

\subsection{LDL particle subclasses (Fig. 1)}

All subclasses of LDL particles were reduced during lipoprotein apheresis (Fig. 1).

The concentration of large LDL particles was reduced from $68.0 \pm 17.5 \mathrm{mg} / \mathrm{dL}$ to $16.3 \pm 2.1 \mathrm{mg} / \mathrm{dL}$ during apheresis $(\mathrm{p}=0.03)$ (Fig. 1a), intermediate LDL particles were reduced from $38.3 \pm 0.6 \mathrm{mg} / \mathrm{dL}$ to $5.0 \pm 3.5 \mathrm{mg} / \mathrm{dL}(\mathrm{p}=0.004)$ (Fig. $1 \mathrm{~b})$ and small LDL particles were reduced from $5.0 \pm 2.6 \mathrm{mg} / \mathrm{dL}$ to $0.2 \pm 0.1 \mathrm{mg} / \mathrm{dL}$ ( $p=0.08$ ) (Fig. 1c). During evolocumab treatment there were no significant changes in the large, intermediate or the small LDL particles, although there seemed to be a slight reduction over time for both large and intermediate particles. Average LDL particle diameter was unchanged during the course of study (data not shown).

\subsection{HDL particle subclasses (Fig. 2)}

All subclasses of HDL particles were reduced during lipoprotein apheresis (Fig. 2), however non-significantly. Large particles were reduced from $5.7 \pm 1.5 \mathrm{mg} / \mathrm{dL}$ to $3.7 \pm 1.2$ $\mathrm{mg} / \mathrm{dL}$, (Fig 2a), intermediate particles were reduced from $15.0 \pm 2.0 \mathrm{mg} / \mathrm{dL}$ to $9.3 \pm 1.2$ $\mathrm{mg} / \mathrm{dL}$, (Fig. 2b), and small HDL particles were reduced from $12.0 \pm 4.6 \mathrm{mg} / \mathrm{dL}$ to $5.0 \pm 1.7 \mathrm{mg} / \mathrm{dL}$, (Fig. 2c). All types of HDL particles increased during the week after lipoprotein apheresis, and were unchanged during treatment with evolocumab.

\subsection{CEC, PON1 activity and SAA1 (Fig. 3)}

There was no significant change in cholesterol efflux capacity during apheresis (42.6 $\pm 3.8 \%$ to $44.8 \pm 8.8 \%$, and no significant changes at week 1 (50.3 $\pm 7.1 \%)$, (Fig. 3a). Likewise, during evolocumab treatment there were no significant changes in efflux capacity. 
There was a significant decrease in PON1 activity during apheresis from $87.5 \pm 8.3 \mathrm{U} / \mathrm{ml}$ to $53.5 \pm 3.6 \mathrm{U} / \mathrm{ml}(p=0.03)$ (Fig. 3b). One week after apheresis PON1 activity had increased to levels comparable to pre-apheresis, and was unchanged during evolocumab treatment.

There was a non- significant reduction in SAA1 during apheresis $(1.9 \pm 1.1 \mu \mathrm{g} / \mathrm{ml}$ to 1.3 $\pm 0.6 \mu \mathrm{g} / \mathrm{ml}(p=0.18)$, and SAA1 was unchanged during evolocumab treatment (Fig. 3c).

The SAA1/PON1 ratio was unchanged during apheresis but appeared to decrease during evolocumab treatment (Fig. 3d). 


\section{Discussion}

We observed reductions in all subclasses of LDL particles after semi-selective lipoprotein apheresis. Although the reduction in small LDL particles did not reach statistical significance it seems numerically convincing, as there were virtually immeasurable amounts of small LDL particles present after apheresis. Subclasses of HDL particles were statistically unaffected by apheresis and evolocumab treatment, even though we previously have demonstrated significant reduction in total HDL cholesterol during apheresis [6]. This could be a result of the low number of participants. There was no significant change in cholesterol efflux capacity one week after apheresis compared to baseline before apheresis, and efflux was also unaffected by evolocumab.

The novel PCSK9 inhibitors have been shown in several clinical trials to lower LDL and coronary atherosclerosis significantly $[4,22,23]$. Clinical endpoints were reduced in a recent evolocumab study, however total mortality was not reduced [5]. Further longterm studies are expected to be reported in 2018. Lipoprotein apheresis, which although time-consuming and expensive - also has a proven clinical effect [24]. Furthermore, whether the intermittent, very low values of LDL seen after apheresis with a rebound before next treatment is preferential to a more constant, moderate reduction seen with PCKS9 inhibition is also a matter of debate. A recent double-blind study has demonstrated that the rate of apheresis treatment can be reduced with PCSK9 inhibition [25]. However, it seems premature to recommend that all patients established in apheresis should be switched to PCSK9 inhibition. 


\subsection{Lipoprotein particle subclasses}

Over the last decades, small LDL particles have been considered especially atherogenic [26], even if the clinical use of fractioning or subclassing of lipoprotein particles has been debated $[27,28]$.

Otto et al have previously demonstrated reduction in large, intermediate and small subfractions of LDL (measured with ultracentrifugation) during one session of lipoprotein apheresis [29], this finding was later confirmed by Geiss et al [30]. The PCSK9 inhibitor alirocumab lowered large, intermediate and small LDL particles (measured by mass spectroscopy) when compared to placebo [31,32]. We demonstrate reductions in large, intermediate and small LDL particles during apheresis, and even if the latter was not statistically significant, virtually all of the small LDL particles were removed. This finding could be of particular importance for $\mathrm{FH}$ patients with high risk of atherosclerotic complications [33]. When changing the treatment from lipoprotein apheresis to evolocumab the findings are less clear; there was a trend for reductions in both large and intermediate LDL particles, while the findings regarding small LDL particles were less consistent and not in line with the findings cited above. This could be due to a number of factors including small sample size and short observation period.

Large HDL particles have previously been associated with better clinical outcome [34], however this notion has been challenged, and more recent studies indicate that smaller HDL particles may be more beneficial [35]. Small, dense HDL particles have also been identified as more efficient mediators of cholesterol efflux [18]. 
Orsoni et al have demonstrated that lipoprotein apheresis reduces all sizes of HDL particles (mass spectroscopy), however relatively more of the larger subtypes of HDL [36]. Koren et al noted a non-significant increase of all three particle sizes after 12 weeks of alirocumab compared to baseline [31]. We found non-significant reductions in all three subclasses of HDL cholesterol particles during apheresis, and no significant differences when changing the cholesterol lowering treatment from apheresis to PCSK9 inhibition.

\subsection{CEC, PON1 activity and SAA1}

Cholesterol efflux capacity is inversely related to atherosclerotic disease in $\mathrm{FH}$ patients [37]. Nenseter et al did not find any change in cholesterol acceptor capacity after lipoprotein apheresis in patients with homozygous FH [38]. Adorni et al demonstrated a reduction in cholesterol efflux capacity after lipoprotein apheresis in patients with hypercholesterolemia [39]. At present, there are few data on PCSK9 inhibition and cholesterol efflux capacity, however an increase in cholesterol efflux during PCSK9 inhibition has been hypothesized $[40,41]$.

A number of previous studies have been performed in non-human cell-lines $[39,42]$. However, in order to avoid any possible species-related differences [43], we routinely use a human monocyte cell line. We demonstrate unchanged cholesterol efflux capacity moving from lipoprotein apheresis to PCSK9 inhibition, even if HDL cholesterol was reduced during lipoprotein apheresis and restored during PCSK9 inhibition. Our contradictory CEC results compared to Adorni et al [39], may be explained by the fact that human monocytes and no acetyl-coenzyme $A$ 
acetyltransferase inhibitor were used in the present study, but this has to be further investigated in a larger study.

PON1 activity is closely connected to HDL function, and could have an atheroprotective effect [44]. PON1 contributes to the antioxidative functions of HDL in the vascular wall but is also an important detoxifying agent [15], therefore techniques measuring enzyme activity may differ depending on the aim. Our finding of reduction of PON1 during apheresis could hence be of importance, also when taking into account the simultaneous reduction in HDL [6]. Furthermore, the return of PON1 to preapheresis levels at the start of PCSK9 inhibition at week 1 and during treatment of evolocumab is interesting and should be further explored in larger studies.

SAA is an acute phase protein, present in HDL in several isoforms ${ }^{45}$ that has been associated with atherosclerotic disease [46], and from previous studies it is known that lipoprotein apheresis reduces serum amyloid A and serum amyloid P [47]. However, in the present study we only find a non-significant reduction in SAA1 during apheresis. Evolocumab treatment had no effect on SAA1 levels.

However, paired measurements of SAA and PON1 have been suggested as a possible marker for dysfunctional HDL since it combines the antioxidant capacity of PON1 with the marker of inflammatory responses SAA [21], and should therefore be investigated in a larger population before any conclusions could be drawn since we have previously shown that apheresis elicits an innate immune response $[48,49]$, and we have recently reported that evolocumab seems inert in this respect [7]. In the present study, the ratio was unchanged after apheresis while treatment with 
evolocumab caused a non-significant reduction. This finding possibly indicates a favorable reduction of SAA1/PON1 with evolocumab treatment but further studies in larger populations are needed.

A very recent paper establishes the need for more data on combination of apheresis and new LDL lowering therapy, and international collaboration is established [50].

\subsection{Limitations}

There are several limitations to this study. It has a low number of participants $(n=3)$ and is merely observational. This limits generalizability. The apheresis method used is a semi-specific method, and may not reflect more specific lipoprotein apheresis systems. Furthermore, the effects seen when converting from lipoprotein apheresis to PCSK9 inhibition may not necessarily reflect the effects of PCSK9 inhibition in apheresis-naïve patients. Finally, some of the non-significant trends seen after seven weeks of treatment may reflect the relatively short observation time.

In conclusion, there were significant reductions in large and intermediate size LDL particles during lipoprotein apheresis, and a non-significant reduction in small LDL particles. There were non-significant reductions in all three subclasses of HDL particles during lipoprotein apheresis, while treatment with evolocumab did not significantly affect LDL or HDL particle subclasses. Cholesterol efflux capacity was not affected by lipoprotein apheresis or evolocumab treatment while the SAA1/PON1 ratio appeared to decrease slightly during evolocumab treatment. 


\section{References}

[1] Gidding SS, Champagne MA, de Ferranti SD, Defesche J, Ito MK, Knowles JW et al. The Agenda for Familial Hypercholesterolemia A Scientific Statement From the American Heart Association. Circulation 2015;132:2167-92.

[2] Schwartz J, Padmanabhan A, Aqui N, Balogun RA, Connelly-Smith L, Delaney M et al. Guidelines on the Use of Therapeutic Apheresis in Clinical Practice-EvidenceBased Approach from the Writing Committee of the American Society for Apheresis: The Seventh Special Issue. J Clin Apher 2016;31:149-62.

[3] Stein EA, Gipe D, Bergeron J, Gaudet D, Weiss R, Dufour R et al. Effect of a monoclonal antibody to PCSK9, REGN727/SAR236553, to reduce low-density lipoprotein cholesterol in patients with heterozygous familial hypercholesterolaemia on stable statin dose with or without ezetimibe therapy: a phase 2 randomised controlled trial. Lancet 2012;380:29-36.

[4] Nicholls SJ, Puri R, Anderson T, Ballantyne CM, Cho L, Kastelein JJ et al. Effect of Evolocumab on Progression of Coronary Disease in Statin-Treated Patients: The GLAGOV Randomized Clinical Trial. JAMA 2016;316:2373-84.

[5] Sabatine MS, Giugliano RP, Keech AC,Honarpour N, Wiviott SD, Murphy SA et al. FOURIER Steering Committee and Investigators Evolocumab and Clinical Outcomes in Patients with Cardiovascular Disease. N Engl J Med 2017;376:1713-22.

[6] Lappegård KT, Enebakk T, Thunhaug H, Hovland A. Transition from LDL apheresis to evolocumab in heterozygous $\mathrm{FH}$ is equally effective in lowering LDL, without lowering HDL cholesterol. Atherosclerosis 2016;251:119-23.

[7] Lappegård KT, Enebakk T, Thunhaug H, Ludviksen JK, Mollnes TE, Hovland A. LDL apheresis activates the complement system and the cytokine network, whereas 
PCSK9 inhibition with evolocumab induces no inflammatory response. J Clin Lipidol 2016;10:1481-87.

[8] Packard C, Caslake M, Shepard J. The role of small, dense low density lipoprotein (LDL): a new look. Int J Cardiol 2000;74:S17-S22.

[9] Diffenderfer MR, Schaefer EJ. The composition and metabolism of large and small LDL. Curr Opin Lipidol 2014;25: 221-26.

[10] Shen H, Xu L, Lu J, Hao T, Ma C, Yang H et al. Correlation between small dense low-density lipoprotein cholesterol and carotid artery intima-media thickness in a healthy Chinese population. Lipids Health Dis 2015;14:137.

[11] Gebhard C, Rhainds D, Tardif JC. HDL and cardiovascular risk: is cholesterol in particle subclasses relevant? Eur Heart J 2015;36:10-12.

[12] Besler C, Lüscher TF, Landmesser U. Molecular mechanisms of vascular effects of High-density lipoprotein: alterations in cardiovascular disease. EMBO Mol Med 2012;4:251-268.

[13] Marsche G, Saemann MD, Heinemann A, Holzer M. Inflammation alters HDL composition and function: implications for HDL-raising therapies. Pharmacology \& therapeutics 2013;137:341-351.

[14] Karlsson $H$, Kontush A, James RW. Functionality of HDL: antioxidation and detoxifying effects. Handb Exp Pharmacol 2015;224:207-28.

[15] Mackness M, Mackness B. Human paraoxonase-1 (PON1): Gene structure and expression, promiscuous activities and multiple physiological roles. Gene 2015;567: 12-21.

[16] Han CY, Tang C, Guevara ME, Wei H, Wietecha T, Shao B et al. Serum amyloid A impairs the antiinflammatory properties of HDL. J Clin Invest 2016;126:266-81. 
[17] Rohatgi A, Khera A, Berry JD, Givens EG, Ayers CR, Wedin KE et al. HDL cholesterol efflux capacity and incident cardiovascular events. $\mathrm{N}$ Engl $\mathrm{J}$ Med 2014;371:2383-93.

[18] Du XM, Kim MJ, Hou L, Le Goff W, Chapman MJ, Van Eck M et al. HDL particle size is a critical determinant of ABCA1-mediated macrophage cellular cholesterol export. Circ Res 2015;116:1133-42.

[19] Sundvold H, Solberg K, Tonstad S, Rødningen OK, Ose L, Berg K et al. A common missense mutation (C210G) in the LDL receptor gene among Norwegian familial hypercholesterolemia subjects. Hum Mutat 1996;7:70-1.

[20] Hoefner DM, Hodel SD, O'Brien JF, Branum EL, Sun D, Meissner I et al. Development of a rapid, quantitative method for LDL subfractionation with use of the Quantimetrix Lipoprint LDL System. Clin Chem 2001;47: 266-74.

[21] Kotani K, Yamada T, Gugliucci A. Paired measurements of paraoxonase 1 and serum amyloid A as useful disease markers. Biomed Res Int 2013;2013:481437. [22] Robinson JG, Farnier M, Krempf M, Bergeron J, Luc G, Averna M et al. ODYSSEY LONG TERM Investigators. Efficacy and safety of alirocumab in reducing lipids and cardiovascular events. N Engl J Med 2015;372:1489-99.

[23] Sabatine MS, Giugliano RP, Wiviott SD, Raal FJ, Blom DJ, Robinson J et al. OpenLabel Study of Long-Term Evaluation against LDL Cholesterol (OSLER) Investigators Efficacy and safety of evolocumab in reducing lipids and cardiovascular events. N Engl J Med 2015;372:1500-9.

[24] Moriarty PM, Hemphill L. Lipoprotein Apheresis. Endocrinol Metab Clin North Am $2016 ; 45: 39-54$ 
[25] Moriarty PM, Parhofer KG, Babirak SP, Cornier MA, Duell PB, Hohenstein B et al. Alirocumab in patients with heterozygous familial hypercholesterolaemia undergoing lipoprotein apheresis: the ODYSSEY ESCAPE trial. Eur Heart J 2016;37:3588-95.

[26] Musunuru K. Atherogenic dyslipidemia: cardiovascular risk and dietary intervention. Lipids 2010;45:907-14.

[27] Krauss RM. Lipoprotein subfractions and cardiovascular disease risk. Curr Opin Lipidol 2010;21:305-11.

[28] Albers JJ, Slee A, Fleg JL, O'Brien KD, Marcovina SM. Relationship of baseline HDL subclasses, small dense LDL and LDL triglyceride to cardiovascular events in the AIM-HIGH clinical trial. Atherosclerosis 2016;251:454-59.

[29] Otto C, Geiss C, Laubach E, Schwandt P. Effects of Direct Adsorption of Lipoproteins Apheresis on Lipoproteins, Low-Density Lipoprotein Subtypes, and Hemorheology in Hypercholesterolemic Patients with Coronary Artery Disease. Ther Apher 2002;6:130-5.

[30] Geiss HC, Bremer S, Barrett PH, Otto C, Parhofer KG. In vivo metabolism of LDL subfractions in patients with heterozygous $\mathrm{FH}$ on statin therapy: rebound analysis of LDL subfractions after LDL apheresis. J Lipid Res 2004;45:1459-67.

[31] Koren MJ, Kereiakes D, Pourfarzib R, Winegar D, Banerjee P, Hamon S et al. Effect of PCSK9 Inhibition by Alirocumab on Lipoprotein Particle Concentrations Determined by Nuclear Magnetic Resonance Spectroscopy. J Am Heart Assoc 2015;4:e002224.

[32] Toth PP, Hamon SC, Jones SR, Martin SS, Joshi PH, Kulkarni KR et al. Effect of alirocumab on specific lipoprotein non-high-density lipoprotein cholesterol and subfractions as measured by the vertical auto profile method: analysis of 3 randomized trials versus placebo. Lipids Health Dis 2016;15:28. 
[33] Krogh HW, Mundal L, Holven KB, Retterstøl K. Patients with familial hypercholesterolaemia are characterized by presence of cardiovascular disease at the time of death. Eur Heart J 2016;37:1398-405.

[34] Lamarche B, Moorjani S, Cantin B, Dagenais GR, Lupien PJ, Després JP et al. Associations of HDL2 and HDL3 subfractions with ischemic heart disease in men. Prospective results from the Québec Cardiovascular Study. Arterioscler Thromb Vasc Biol 1997;17:1098-105.

[35] Martin SS, Khokhar AA, May HT, Kulkarni KR, Blaha MJ, Joshi PH et al on behalf of the Lipoprotein Investigators Collaborative (LIC). HDL cholesterol subclasses, myocardial infarction, and mortality in secondary prevention: the lipoprotein investigators collaborative. Eur Heart J 2015;36:22-30.

[36] Orsoni A, Saheb S, Levels JH, Dallinga-Thie G, Atassi M, Bittar R et al. LDLapheresis depletes apoE-HDL and pre- $\beta 1-H D L$ in familial hypercholesterolemia: relevance to atheroprotection. J Lipid Res 2011;52:2304-13.

[37] Ogura M, Hori M, Harada-Shiba M. Association Between Cholesterol Efflux Capacity and Atherosclerotic Cardiovascular Disease in Patients With Familial Hypercholesterolemia. Arterioscler Thromb Vasc Biol 2016;36:181-8.

[38] Nenseter MS, Narverud I, Græsdal A, Bogsrud MP, Aukrust P, Retterstøl K et al. Cholesterol efflux mediators in homozygous familial hypercholesterolemia patients on low-density lipoprotein apheresis. J Clin Lipidol 2013;7: 109-16.

[39] Adorni MP, Zimetti F, Puntoni M, Bigazzi F, Sbrana F, Minichilli F et al. Cellular cholesterol efflux and cholesterol loading capacity of serum: effects of LDL-apheresis. J Lipid Res 2012;53:984-9. 
[40] Shen L, Peng HC, Nees SN, Zhao SP, Xu DY. Proprotein convertase subtilisin/kexin type 9 potentially influences cholesterol uptake in macrophages and reverse cholesterol transport. FEBS Lett 2013;587:1271-4.

[41] Ferri N, Corsini A, Macchi C, Magni P, Ruscica M. Proprotein convertase subtilisin kexin type 9 and high-density lipoprotein metabolism: experimental animal models and clinical evidence. Transl Res 2016;173:19-29.

[42] Khera AV, Cuchel M, de la Llera-Moya M, Rodrigues A, Burke MF, Jafri K et al. Cholesterol efflux capacity, high-density lipoprotein function, and atherosclerosis. N Engl J Med 2011;364:127-35.

[43] Gordon SM, Li H, Zhu X, Shah AS, Lu LJ, Davidson WS. A comparison of the mouse and human lipoproteome: suitability of the mouse model for studies of human lipoproteins. J Proteome Res 2015;14:2686-95.

[44] Macharia M, Hassan MS, Blackhurst D, Erasmus RT, Matsha TE. The growing importance of PON1 in cardiovascular health: a review. J Cardiovasc Med 2012;13:443-53.

[45] Levels JH, Geurts P, Karlsson H, Marée R, Ljunggren S, Fornander L et al. Highdensity lipoprotein proteome dynamics in human endotoxemia. Proteome Sci 2011;9:34.

[46] Sun L, Ye RD Serum amyloid A1: Structure, function and gene polymorphism. Gene 2016;583:48-57.

[47] Palumbo B, Cardinali L, Sinziger H. LDL-Apheresis Removes Serum Amyloid P and A in Hypercholesterolemic Patients. Thrombosis Research 2000;97:491-94.

[48] Hovland A, Hardersen R, Sexton J, Mollnes TE, Lappegård KT. Different inflammatory responses induced by three LDL-lowering apheresis columns. J Clin Apher 2009;24:247-53. 
[49] Hovland A, Hardersen R, Nielsen EW, Enebakk T, Christiansen D, Ludviksen JK et al. Complement profile and activation mechanisms by different LDL apheresis systems. Acta Biomater 2012; 8: 2288-96.

[50] Stefanutti C, Julius U, Watts GF, Harada-Shiba M, Cossu M, Schettler VJ et al. Toward an international consensus-Integrating lipoprotein apheresis and new lipidlowering drugs. J Clin Lipidol 2017;11:858-71. 
Figures.
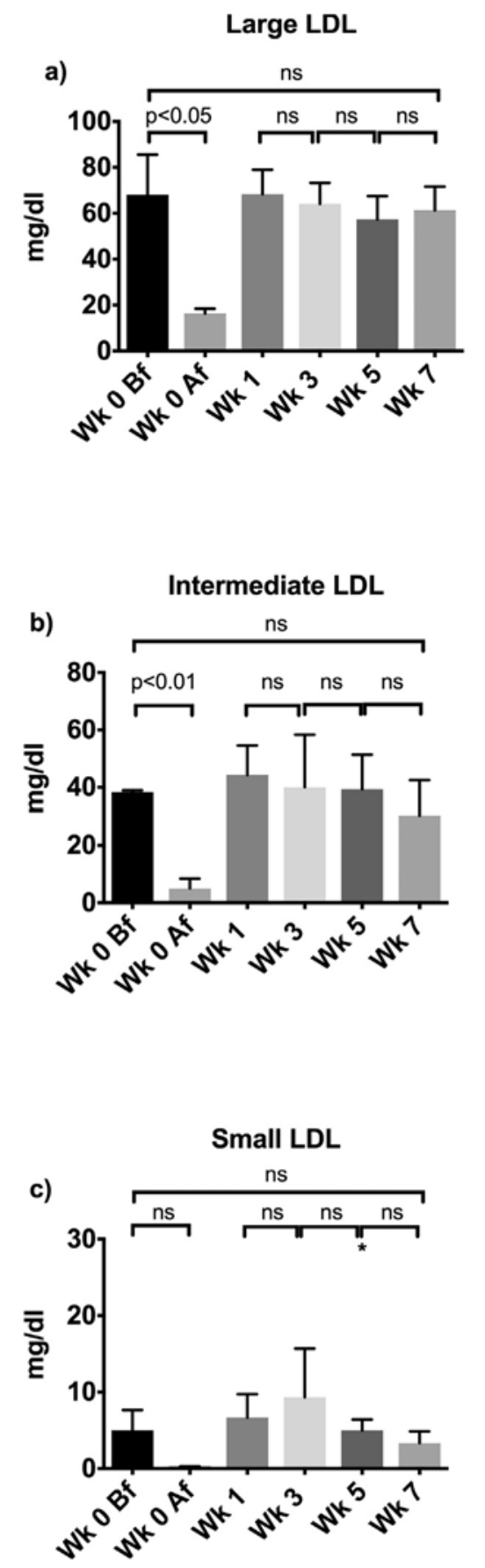

Figure 1. Concentrations of subclasses of LDL particles during lipoprotein apheresis and after starting evolocumab.

LDL: Low-density lipoprotein. Wk 0 bf: Week 0 before apheresis. Wk 0 af: Week 0 after apheresis. Wk 1-7: Week 1-7 (samples taken before evolocumab administration). 


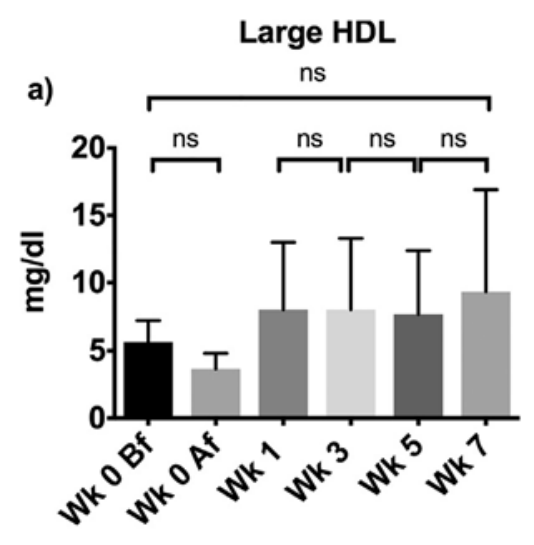

Intermediate HDL
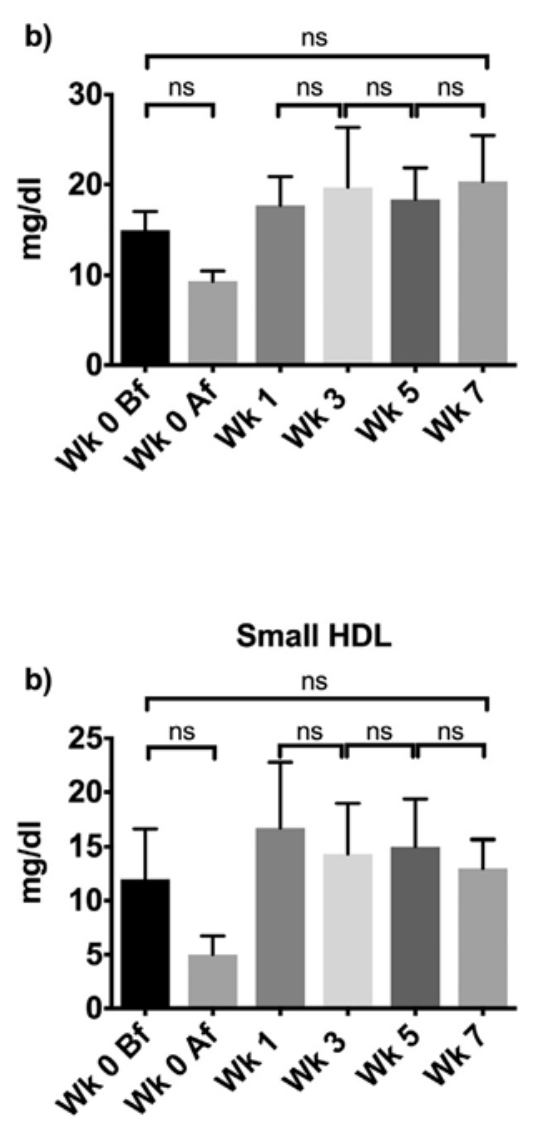

Figure 2. Concentrations of subclasses of HDL particles during lipoprotein apheresis and after starting evolocumab.

HDL: High-density lipoprotein. Wk 0 bf: Week 0 before apheresis. Wk 0 af: Week 0 after apheresis. Wk 1-7: Week 1-7 (samples taken before evolocumab administration). 

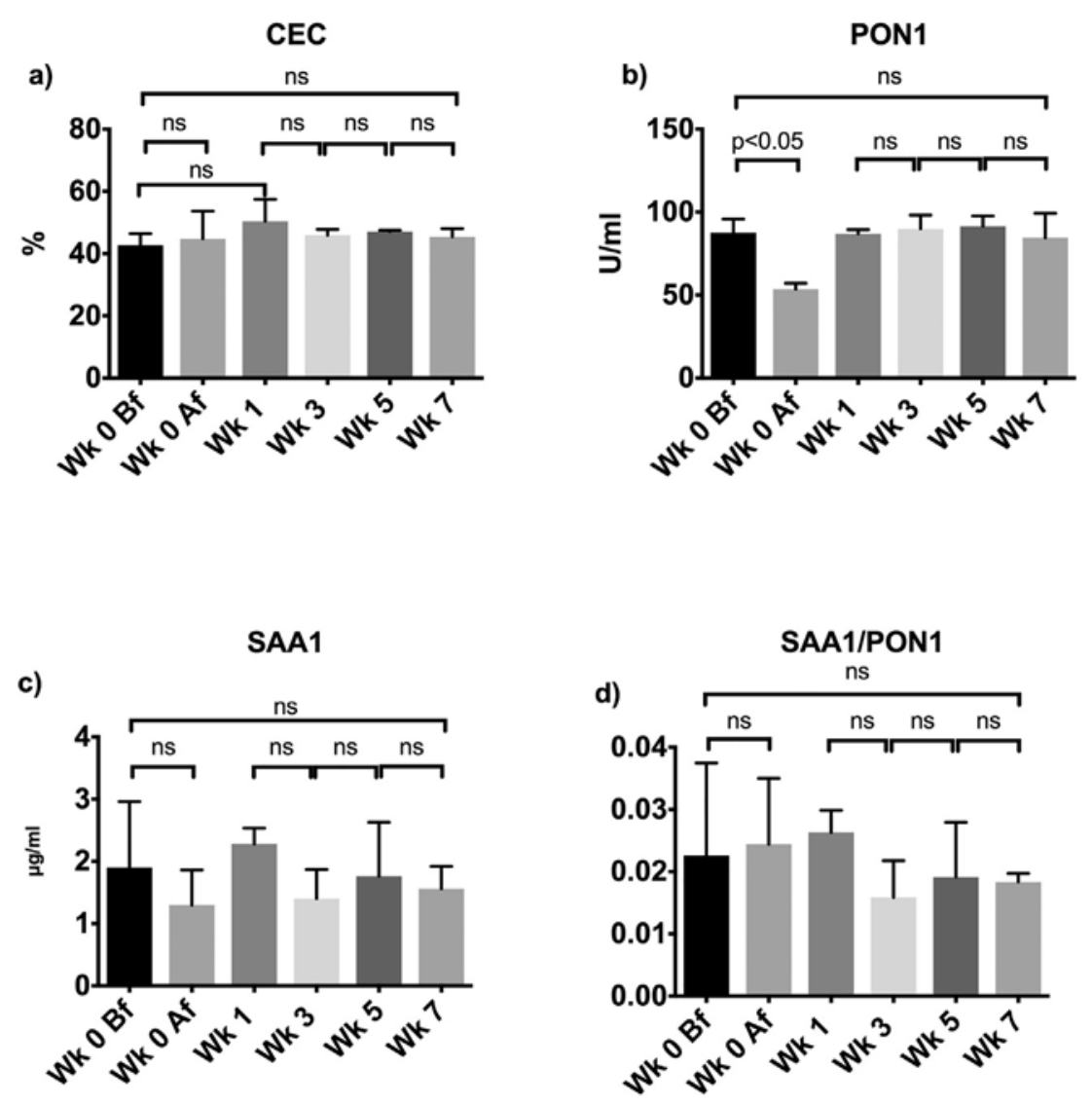

Figure 3. Cholesterol efflux capacity, PON1 activity, SAA1 concentration and PON1/SAA1 ratio during lipoprotein apheresis and after starting evolocumab.

CEC: Cholesterol efflux capacity. PON1: paraoxonase-1. SAA1: serum amyloid A1. Wk 0 bf: Week 0 before apheresis. Wk 0 af: Week 0 after apheresis. Wk 1-7: Week 17 (samples taken before evolocumab administration). 